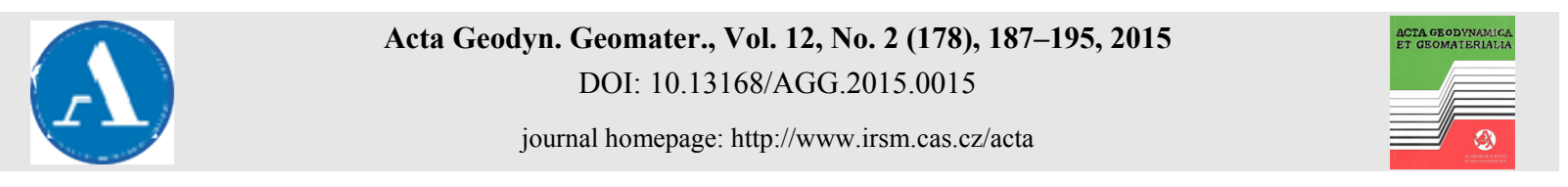

ORIGINAL PAPER

\title{
INFLUENCE OF GRAIN SIZE, HUMIDITY AND STATE OF STRESS ON THE MECHANICAL PROPERTIES OF SANDSTONES
}

\author{
Mirosława BUKOWSKA
}

Central Mining Institute, 40-166 Katowice, Plac Gwarków 1,Poland

*Corresponding author's e-mail: mbukowska@gig.eu

\begin{tabular}{l} 
ARTICLE INFO \\
\hline Article history: \\
Received 10 December 2014 \\
Accepted 8 April 2015 \\
Available online 3 June 2015
\end{tabular}

Keywords:

Sandstone

Humidity of rocks

Mechanical properties

Triaxial compression tests

\begin{abstract}
Results of conventional triaxial compression tests on medium-grained and fine-grained sandstone samples of the Upper Silesian Coal Basin in Poland, under a full range of strain and two states of humidity, in the air-dry state and capillary saturation state, are presented. The geomechanical properties in the pre-peak and post-peak sections of the stress-strain curve are determined, as well as the equations of the envelope of Mohr's circles, the cohesion, and the internal friction angle. We conducted tests that showed the tendencies of the changes in the stress and strain parameters resulting from confining pressure. The dependence of the critical differential stress, residual differential stress, critical strain, and total strain on the confining pressure were described by linear functions. The dependence of the post-peak failure modulus on the confining pressure for the tested sandstones in an air-dry state was described by a polynomial function. In the tests of sandstones in the capillary saturation state we did not obtain reliable results and further research is required in this area. There are few studies showing the influence of humidity on the pre-peak and post-peak parameters of rocks undergoing conventional triaxial compression tests in a servo controlled testing machine. Our test results have practical applications in forecasting the behavior of rocks located deep underground and in designing safe mining operations.
\end{abstract}

\section{INTRODUCTION}

When considering possible natural hazard risks in the Carboniferous rock mass of the mined rock formations of the Upper Silesian Coal Basin (USCB) the weakening influence of water on certain properties of rocks, e.g. geomechanical ones is an important issue. Mining activity, especially in the areas exploited for a few decades, is associated with drainage of the rock mass and changes in the water content of the rock. The water content in the Carboniferous rock mass of the USCB is associated with the rock structure and the water sources. The hydrogeological cross-section of the USCB Upper Carboniferous reveals aquifers, mostly porous and fractured, consisting of sandstones and conglomerates. The presence of sandstones in the mined Carboniferous rock mass is one of the factors contributing to certain natural hazards. Methane hazard in the longwalls where sandstones occur in the immediate roof and/or floor of the mine (Krause and Smoliński, 2013) or water hazards associated with dislocation zones and pillars in the vicinity of abandoned and flooded collieries (Bukowski, 2009) and mine shafts (Bukowski, 2011) are examples of such hazards.

The distribution of sandstones and conglomerates in the vertical cross-section of the USCB upper Carboniferous varies (Fig. 1).
In the southwestern part of the USCB in Poland (impenetrable for water) Carboniferous formations are covered with a thick layer of impermeable rocks. This results in reduced water supply in the rock mass compared with other areas of the USCB. Mining activities are conducted there in the layers of the Mudstone Series and Paralic Series (marginal upper beds). The Mudstone Series in particular are characterized by a low percentage of water-absorbing rocks compared with the lithostratigraphic units of the USCB Upper Carboniferous (Fig. 1). The water inflow to the collieries in the area is 0.2 to $3.3 \mathrm{~m}^{3} / \mathrm{min}$. Only in the area of a hydro-geological window, the inflow reaches about to $6 \mathrm{~m}^{3} / \mathrm{min}$. In the northeastern and eastern part of the USCB, the water content in the Carboniferous formations is associated with the occurrence of sandstones of the Cracow Sandstone Series and Upper Silesian Sandstone Series. In this area the productive Carboniferous strata is not fully separated from the surface and is abundantly supplied with water. The natural inflow to the collieries in the area is between 2 to $20 \mathrm{~m}^{3} / \mathrm{min}$, up to a maximum of $60 \mathrm{~m}^{3} / \mathrm{min}$. In the central and western part of the USCB the coal seams occur together with rocks that contain small amounts of water-absorbing rocks. Rock mass drained of free water has lower values of open porosity and a specific yield of water-absorbing rocks. In the areas which are not fully separated from the 


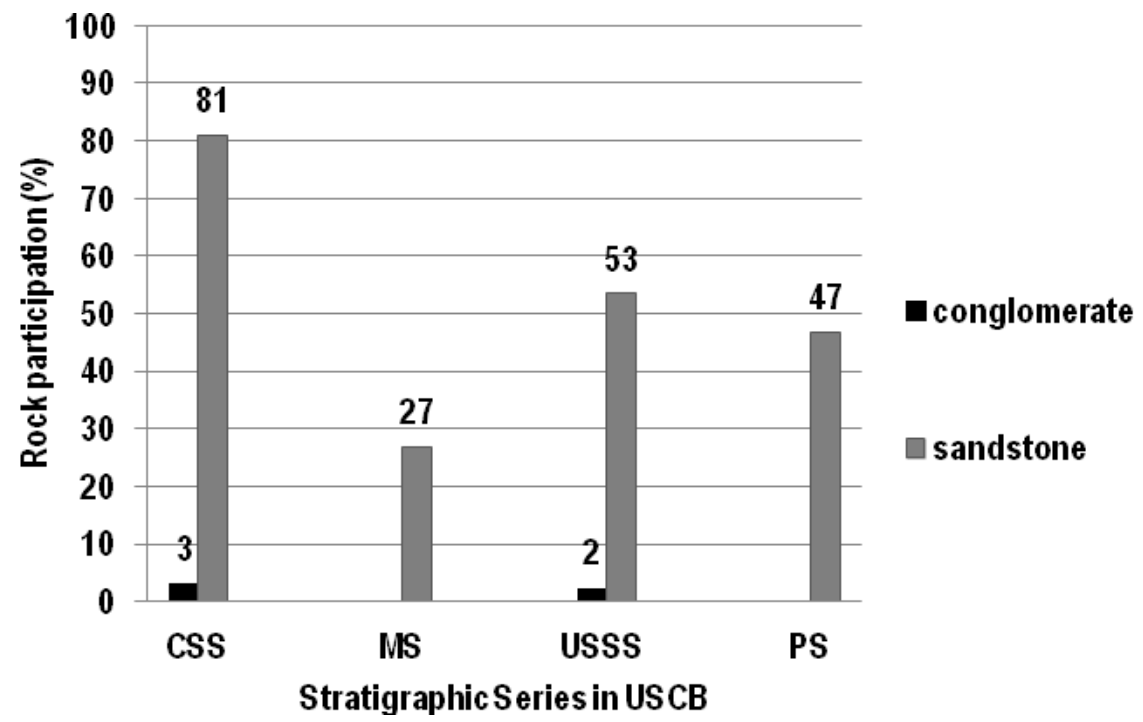

Fig. 1 Percentage of clastic rocks in cyclothems of Upper Carboniferous in USCB: CSS - Cracow Sandstone Series; MS - Mudstone Series; USSS - Upper Silesian Sandstone Series; PS - Paralic Series

surface and abundantly supplied with water, the strength-strain parameters of the rocks forming the Carboniferous rock mass are similar to the parameters of rocks tested with their pores partially saturated with water, while in the areas impenetrable to water (unfavorable conditions of water supply to the rock mass) the parameters are similar to those measured in the so-called air-dry state - similar to the full drainage state of the rock mass.

Considering the above-mentioned data, to improve the methodology of assessing the natural hazard risks in the USCB, including seismic hazards and rock bursts (Stec, 2009, 2012; Kabiesz, 2010), water hazards (Bukowski, 2010) and impacts of underground coal-mining activity on the environment with a special emphasis on groundwater guality (Grmela and Rapantova, 2003; Rapantova and Grmela, 2003), and radiation hazards (Wysocka, 2010; Ball and Wysocka, 2011) we tested the geomechanical properties of Carboniferous sandstones at different states of humidity and various load conditions, through the full range of their deformation. We also considered the fact that, as a result of mining activity, the rock mass is destroyed (Majcherczyk et al. 2005). Around underground operations a destruction zone of the rock mass occurs; therefore, it is necessary to predict the deformation of the rock mass, assess the stability of the underground operations (Majcherczyk et al., 2006). Currently, these assessments are achieved by numerical calculations and the full stress-strain characteristics of the rocks are considered. Changing states of humidity in the rock mass resulting from different hydrogeological conditions in the rock surrounding the underground operations influence the safety of both mining activities and liquidation works.

\section{METHODOLOGY OF TESTS ON SANDSTONES IN DIFFERENT STATES OF WATER SATURATION IN CONVENTIONAL TRIAXIAL COMPRESSION TESTS}

We conducted tests of the geomechanical parameters of cylindrical samples of medium-grained and fine-grained sandstone of different humidity, under conventional triaxial compression. The sandstone samples were collected from the formation of the Upper Silesian sandstone series. Mediumgrained sandstone was collected from the Ruda beds and fine-grained sandstone from the saddle beds.

Conventional triaxial compression tests were conducted in a servo controlled MTS-815 testing machine, where the vertical pressure on the rock sample is produced with a moving plate and oil is the confining pressure medium. The testing machine was controlled at a longitudinal strain rate of $10^{-5} \mathrm{~s}^{-1}$, measured in the measuring system of the press with piston stroke.

The conventional triaxial compression tests were conducted on cylindrical samples of $30 \mathrm{~mm}$ diameter and slenderness ratio of 2 . The tests followed the schematics of a classical individual test (Kovari et al,. 1983). Four values of confining pressure were used: 0, 15,25 , and $40 \mathrm{MPa}$. Total tested 80 samples - the samples 5 for each circular pressure. The samples in the testing machine were compressed perpendicular to the layering direction. The laboratory tests of the sandstone geomechanical parameters were conducted according to our own research procedures and those based on the ISRM recommendations (Ulusay and Hudson, 2007).

Many researchers have shown that an increase in the value of the confining pressure leads to an increase in the strength of the rocks and to a transition from 


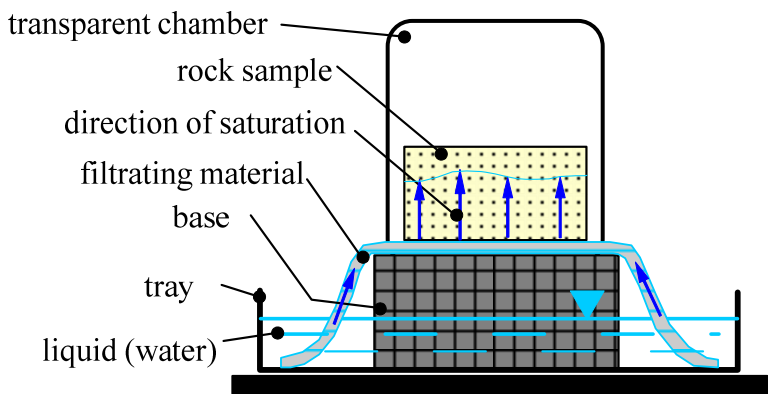

Fig. 2 Device for determination of gravity drainage capacity by capillary saturation method regular solid rock sample (Bukowski, 2007).

a state of brittle fracture to ductile flow at high confining pressure (Mogi, 1964, 1971; Bieniawski, 1971; Paterson, 1978; Pinińska, 2007; Łukaszewski, 2007). The post-peak section of the stress-strain curve shows a decrease in stress indicating that with the increase in the confining pressure the value of the residual stress also increases, and the post-peak curve has a gentler slope towards the strain axis. This results in lower values of the post-peak failure modulus, which reflects the dynamics of rock destruction in the post-failure range, and higher values of residual stress.

In laboratory conditions the geomechanical properties of Carboniferous rocks are tested in various states of humidity. These are: the state reflecting humidity in a newly cut sample after going through water scrubber; the state up to 48 hours after cutting; the humidity after remaining in water for between a few and several dozen hours; the state of humidity obtained through moisturizing for 24 hours under high pressure (10 $\mathrm{MPa})$; the humidity after decreasing moisture content through drying at temperatures of $105-110{ }^{\circ} \mathrm{C}$ for up to several dozen hours; the humidity after leaving the sample in room temperature for up to 24 hours.

Fine-grained and coarse-grained sandstones from the upper Carboniferous USCB in Poland were tested in various states of water saturation - in the so-called air-dry state and in capillary saturation. The capillary saturation state of rocks is associated with the phenomenon of active capillarity. In laboratory conditions, the capillary saturation state is the closest state that can approximate the natural humidity conditions in the rock mass. The humidity conditions in the rock mass change as a result of drainage and the influence of mining activity. In laboratory conditions, the capillary saturation state is obtained by placing a rock sample on capillary filtration material which remains in contact with the sample and water can then be absorbed into the sample by capillary action (Fig. 2). It is worth noting that the capillary saturation state, obtained according to the methodology of hydrogeological tests, was used here for the first time in geomechanical triaxial compression tests of rocks.

\section{RESULTS OF GEOMECHANICAL PARAMETER TESTS OF SANDSTONES IN VARIOUS STATES OF SATURATION}

During conventional triaxial compression of sandstone samples in two states of humidity the following values were determined (Figs. 3, 4):

- critical strain determined at maximum stress $\left(\varepsilon_{\mathrm{cr}}\right)$,

- residual strain in the post-peak section of the stress-strain curve, which reflects residual stress $\left(\varepsilon_{\text {res }}\right)$,

- post-peak failure modulus (M),

- differential residual stress $\left(\sigma_{\mathrm{res}}-\sigma_{3}\right)$,

- critical differential stress $\left(\sigma_{1}-\sigma_{3}\right)$,

and

- internal friction angle $(\phi)$ and cohesion (c) (from Mohr's circle).

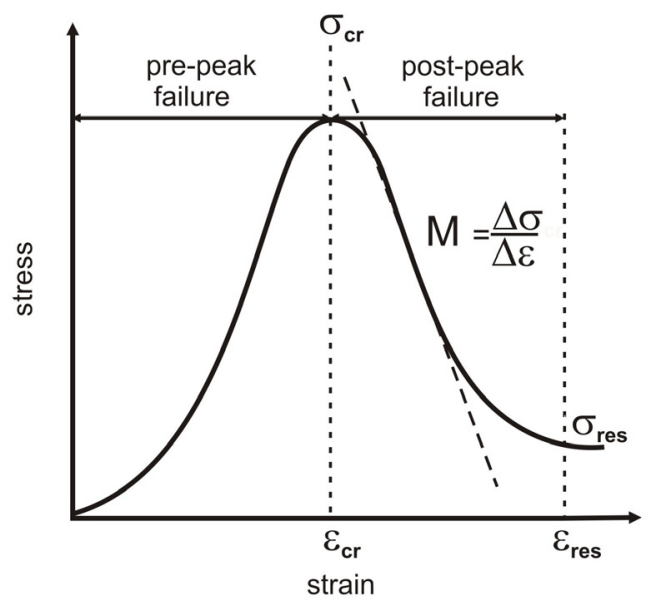

Fig. 3 Idealized stress-strain curve and geomechanical properties.

Based on the conventional triaxial compression test results for the entire strain range of each sample (pre-peak and post-peak range), we derived the relationships between the confining pressure and the individual parameters for the two states of humidity of the sandstones.

Figures 5-14 show the dependence of the geomechanical parameters on the confining pressure applied in the tests. The results for the differential stress, the critical strain, and the residual stress were fitted with functions with high correlation coefficients.

Critical differential stress: the dependence between the confining pressure $(0-40 \mathrm{MPa})$ and the critical differential stress (Figs. 5, 6) for mediumgrained and fine-grained sandstone can be described by a linear function with correlation coefficients of between 0.960 and 0.993. Based on tests that 


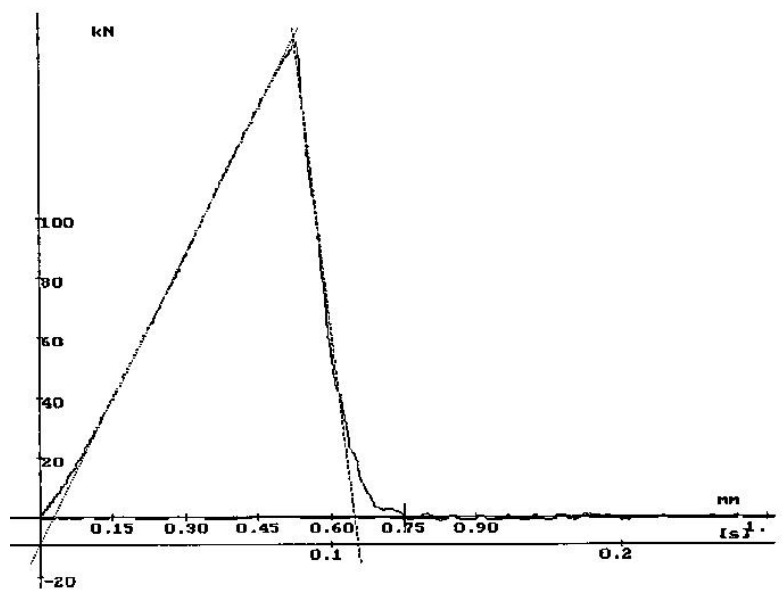

a)

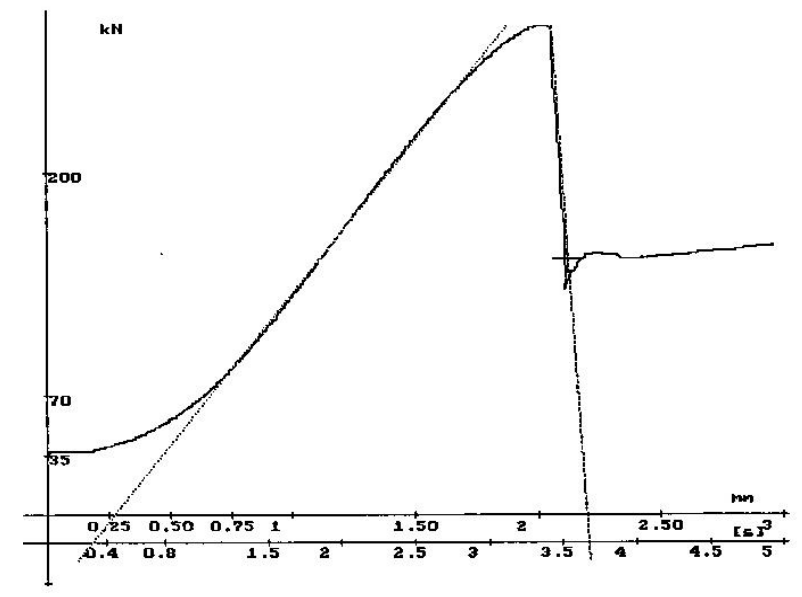

b)

Fig. 4 The course of force $(\mathrm{kN})$-displacement $(\mathrm{mm})$, time $(\mathrm{sec})$ curves for fine-grained sandstone at confining pressure of:

a) $0 \mathrm{MPa}$; b) $40 \mathrm{MPa}$ (own research)

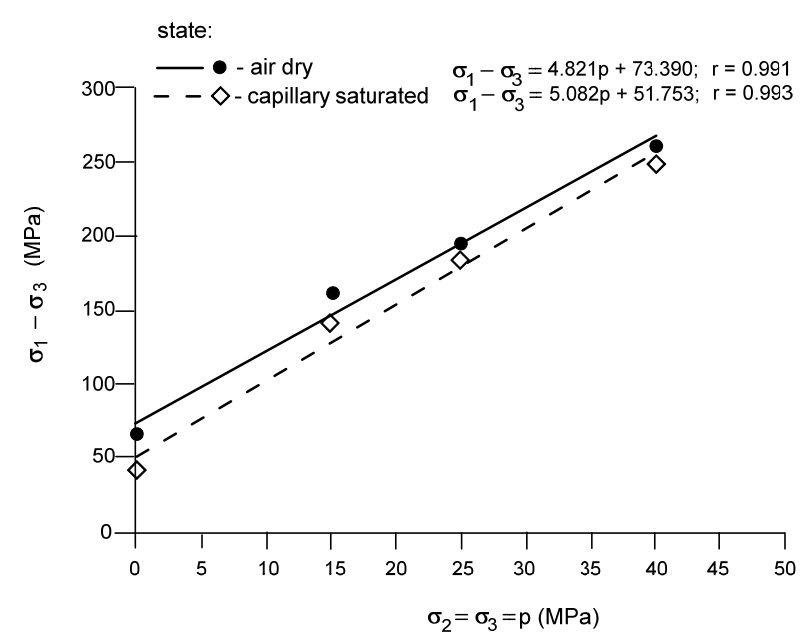

Fig. 5 Dependence of the critical differential stress on the confining pressure for medium-grained sandstone.

destroyed rocks under conventional triaxial compression, Kwaśniewski (2002) proposed that at low confining pressure, rocks can show "an effect of high pressure sensitivity of strength caused by cracking rocks". This is expressed as a convexity of the stress-strain curve towards the axis of the strength limit. This effect is caused by structural defects in the rock (closing of microcracks and pores as a result of loading and fitting the plates of the testing machine to the surface of the sample). That is why the graph does not start in the $(0,0)$ coordinate point. The dependence of the critical differential stress on the confining pressure in the applied range of confining pressure up to $40 \mathrm{MPa}$ for the tested sandstone samples was approximated with a straight line.

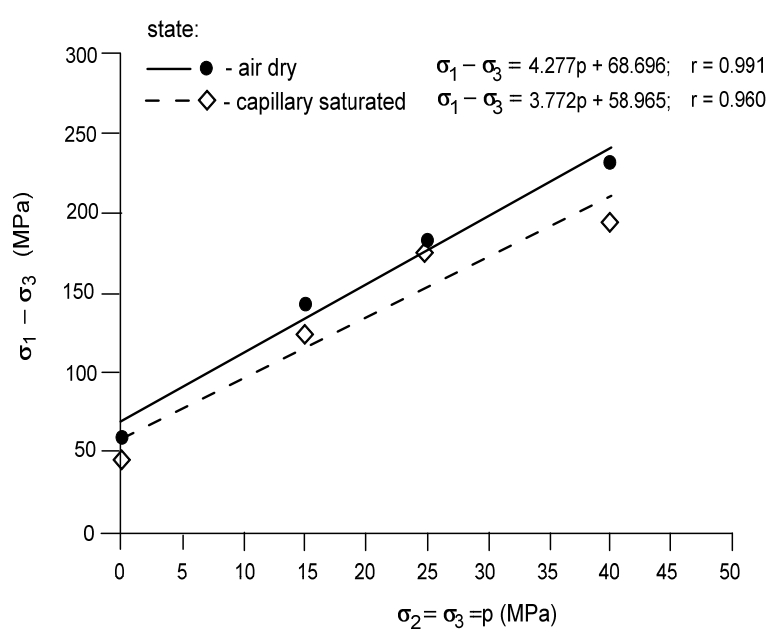

Fig. 6 Dependence of the critical differential stress on the confining pressure for fine-grained sandstone.

Kwaśniewski (2002) presented a similar graph of the discussed dependence for some rocks after the initial compaction of the samples, at low confining pressure. The literature shows that at high values of confining pressure $(\geq 100 \mathrm{MPa})$, when the rock transits from a state of brittle fracture to ductile flow, curvilinear graphs are more common (Gustkiewicz, 1999).

Analysis of the test results shows an increase in the value of the differential stress accompanying an increase in the confining pressure. The increase in the confining pressure of $40 \mathrm{MPa}$ enabling tests to be conducted at a confining pressure of $0 \mathrm{MPa}$ is:

- a 3.6- and 4.3-fold increase for medium-grained sandstone and fine-grained sandstone tested in an air-dry state, respectively; 


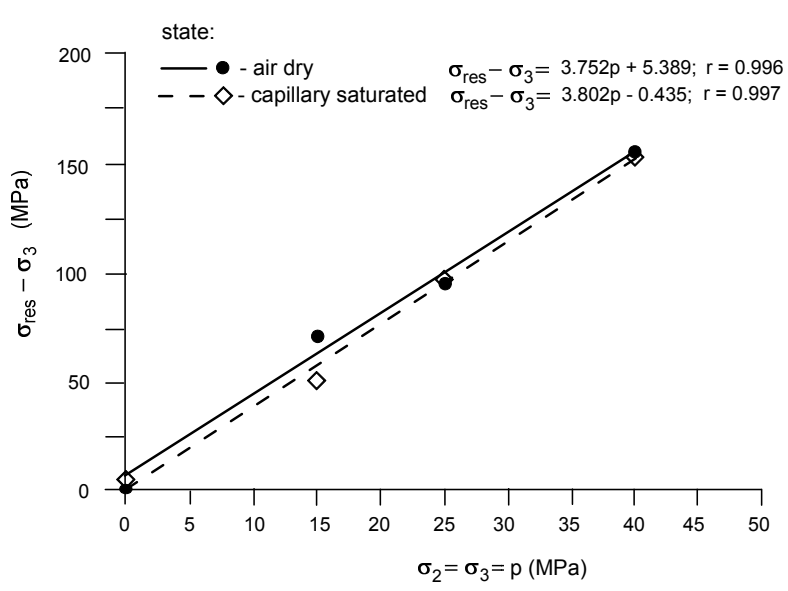

Fig. 7 Dependence of the residual differential stress on the confining pressure for medium-grained sandstone

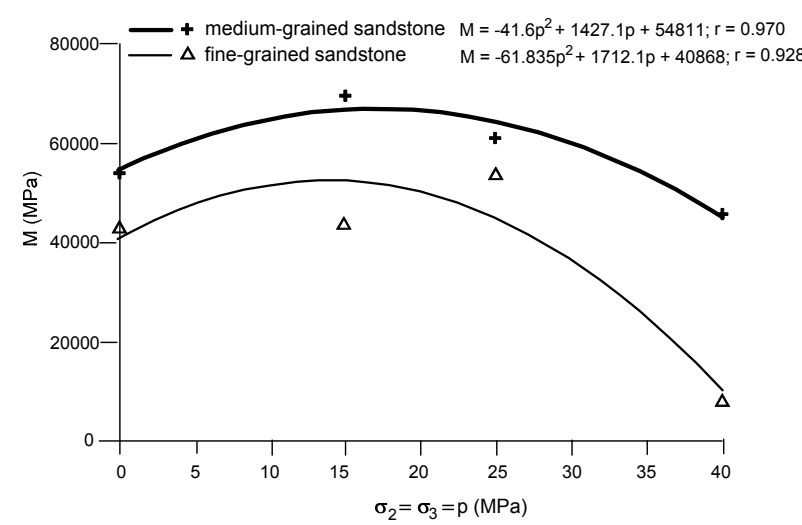

Fig. 9 Dependence of the post-peak failure modulus on the confining pressure for sandstone in an air-dry state.

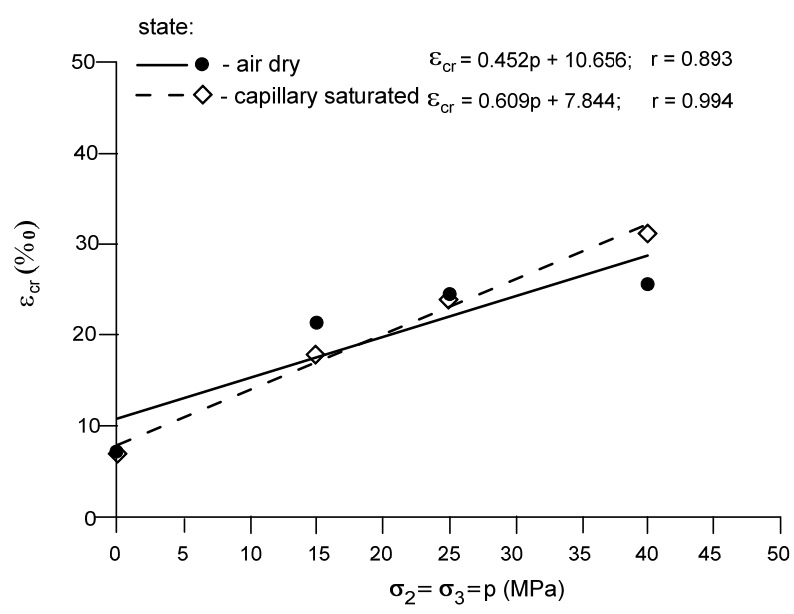

Fig. 11 Dependence of the critical strain on the confining pressure for medium-grained sandstone.

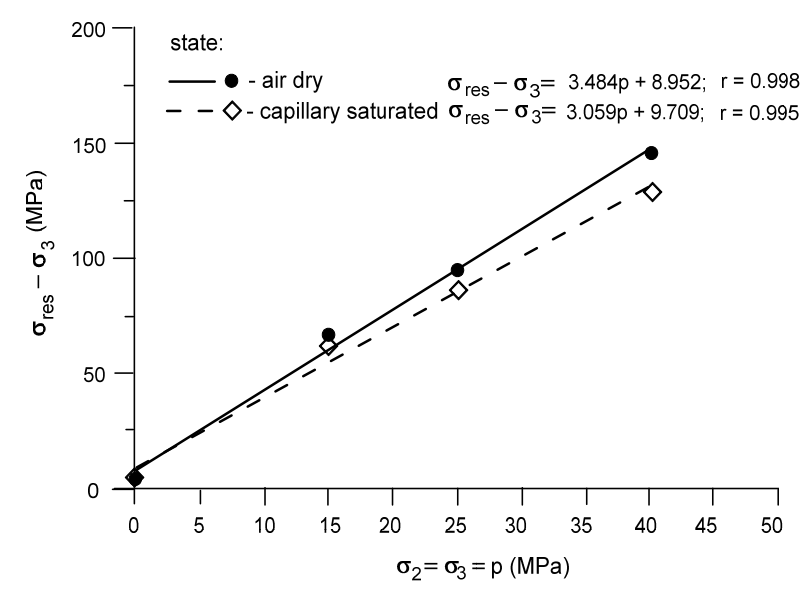

Fig. 8 Dependence of the residual differential stress on the confining pressure for fine-grained sandstone.

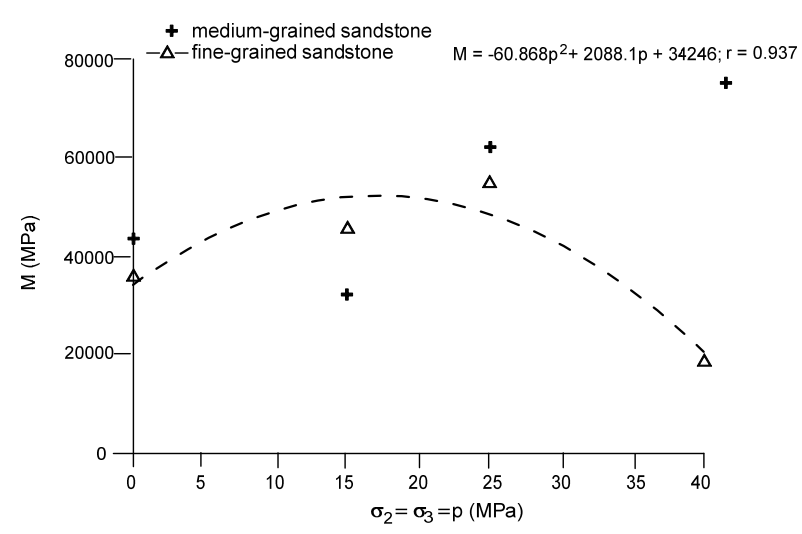

Fig. 10 Dependence of the post-peak failure modulus on the confining pressure for sandstone in a capillary saturation state.

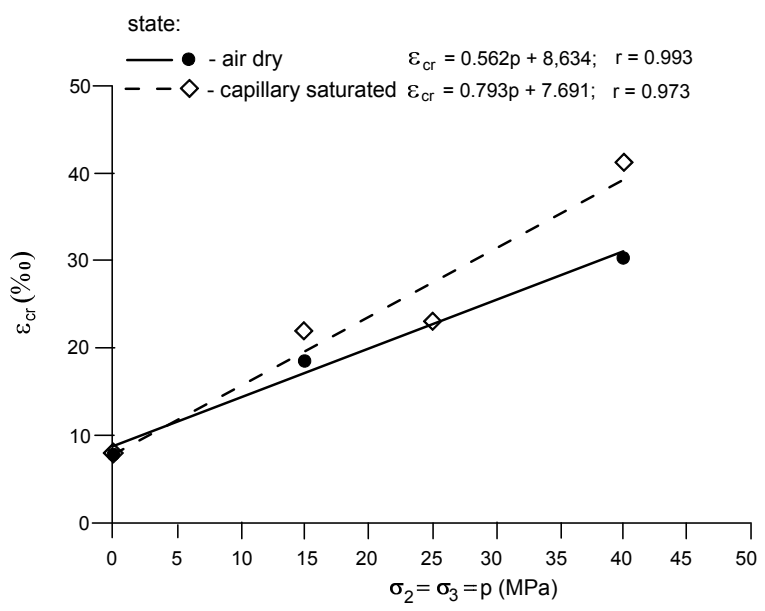

Fig. 12 Dependence of the critical strain on the confining pressure for fine-grained sandstone. 


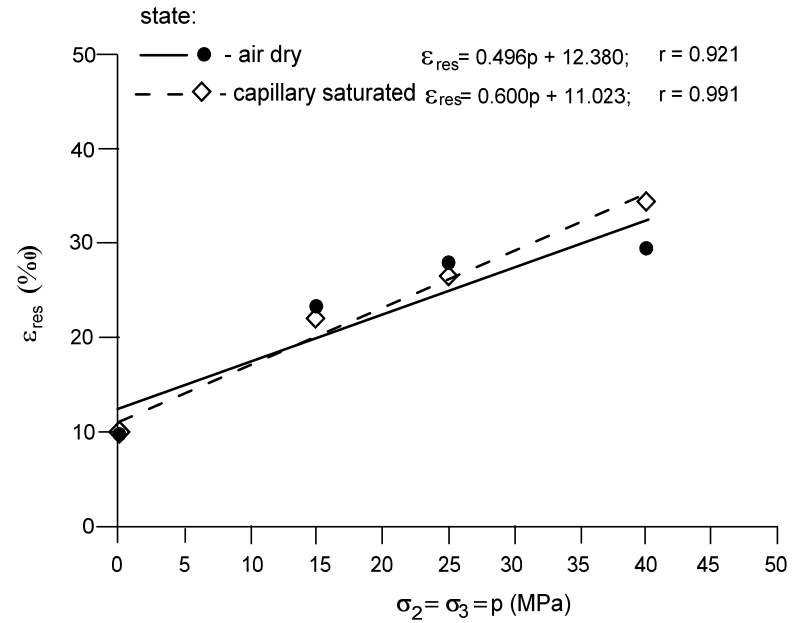

Fig. 13 Dependence of the residual strain on the confining pressure for medium-grained sandstone.

- a 4.3- and 5.8-fold increase for fine-grained sandstone and medium-grained sandstone tested in the capillary saturation state, respectively.

We also observed a bigger increase in the differential stress for large-grain sandstone tested in the capillary saturation state.

The tests confirm the increase in the differential stress accompanying an increase in the confining pressure is lower for sedimentary rocks than for igneous rocks, e.g. for granite the difference in the differential stress associated with the increase in the confining pressure in the range of $20-50 \mathrm{MPa}$ is $100 \%$ (Li et al., 1999). Moreover, Bukowska and Sanetra (2008) showed that in a confining pressure of 0-70 $\mathrm{MPa}$, the differential stress for granite from Strzegom beds (Poland) showed a 5-7.5-fold increase.

Residual differential stress: our results show that the dependence of the residual stress on the confining pressure can be approximated by a linear function, for which we obtained a correlation coefficient of $0.995-0.998$ (Figs. 7, 8). An increase in the confining pressure up to $40 \mathrm{MPa}$ caused a $26-$ to 78 -fold increase in the differential residual stress for sandstone in the air-dry state and a 25 - to 46-fold increase for sandstones in the capillary saturation state. At the same time, a bigger increase in the differential residual stress was observed within the pressure range of $0-40 \mathrm{MPa}$ for larger-grained sandstone. The increase in some way shows the dynamics of the transition from the state of brittle fracture to ductile flow during the loading process.

Post-peak failure modulus: the tests conducted on sandstone showed that the dependence of the postpeak failure modulus on the confining pressure in 0 $40 \mathrm{MPa}$ of pressure can be described by a polynomial function with high correlation coefficients of between 0.928 and 0.970 (Fig. 9). Only the post-peak failure

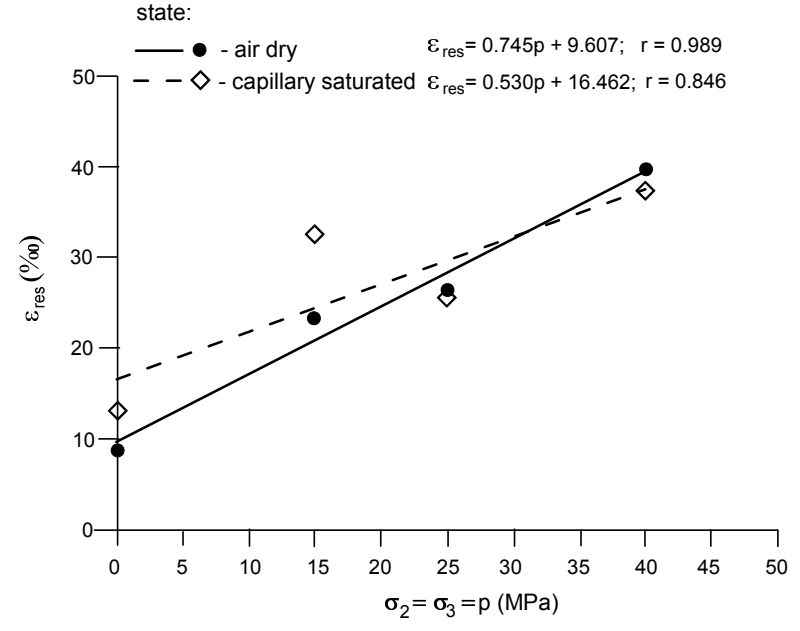

Fig. 14 Dependence of the residual strain on the confining pressure for fine-grained sandstone.

modulus of the medium-grained sandstone samples tested in the capillary saturation state showed an upward tendency accompanying an increase in the confining pressure and did not reach the minimum value at a confining pressure of $40 \mathrm{MPa}$ (Fig. 10). It is worth noting that at low confining pressures, the postpeak failure modulus changes irregularly and there is an apparent decrease in the post-peak failure modulus only at higher pressures (40 $\mathrm{MPa})$. At the confining pressure of $40 \mathrm{MPa}$, comparing with the value obtained at $0 \mathrm{MPa}$, there was a decrease in the postpeak failure modulus by $15 \%$ for medium-grained sandstone, and by an impressive $81 \%$ for fine-grained sandstone, both tested in an air-dry state. The finegrained sandstone tested in the capillary saturation state showed a decrease of $48 \%$ in the post-peak failure modulus.

Critical strain and residual strain: the changes in the critical strain and residual strain caused by increases in the confining pressure are presented in Figures 11-14. The dependence for the tested sandstone in the applied confining pressure of 0 $40 \mathrm{MPa}$ can be described by a linear function, for which we obtained a correlation coefficient of between 0.846 and 0.994 . The most significant increase in the critical strain (3-fold) was observed in the confining pressure range of $0-15 \mathrm{MPa}$. A further increase in the confining pressure to $40 \mathrm{MPa}$ resulted in a 5-fold increase in the critical strain. Note that sandstone in the water capillary saturation state shows bigger changes in the critical strain. Increasing the confining pressure in the applied range influences the residual strain in a similar fashion. At a confining pressure of $40 \mathrm{MPa}$ in the medium-grained sandstone there was a 3- to 3.5-fold increase in the residual strain and a 4.5-fold increase in sandstone in the airdry state, compared with the values obtained at a confining pressure of $0 \mathrm{MPa}$. 
Table 1 Equations of the parabolic envelope of Mohr's circles of the tested sandstones.

\begin{tabular}{lcc}
\hline \multicolumn{1}{c}{ Rock } & Air-dry state & Capillary saturation state \\
\hline Medium-grained sandstone & $\tau^{2}=101.26\left(\sigma_{\mathrm{n}}+4.89\right)$ & $\tau^{2}=94\left(\sigma_{\mathrm{n}}+4.06\right)$ \\
Fine-grained sandstone & $\tau^{2}=84.68\left(\sigma_{\mathrm{n}}+7.84\right)$ & $\tau^{2}=71.5\left(\sigma_{\mathrm{n}}+6.58\right)$ \\
\hline
\end{tabular}

Table 2 Internal friction angle and cohesion of sandstone for air-dry state and capillary saturation state.

\begin{tabular}{lcccccc}
\hline \multirow{2}{*}{ Rock } & \multicolumn{3}{c}{ Air-dry state } & \multicolumn{3}{c}{ Capillary saturation state } \\
\cline { 2 - 7 } & $\begin{array}{c}\mathrm{UCS}, \\
{[\mathrm{MPa}]}\end{array}$ & $\begin{array}{c}\text { Internal friction } \\
\text { angle [degrees] }\end{array}$ & $\begin{array}{c}\text { Cohesion } \\
{[\mathrm{MPa}]}\end{array}$ & $\begin{array}{c}\text { UCS, } \\
{[\mathrm{MPa}]}\end{array}$ & $\begin{array}{c}\text { Internal friction } \\
\text { angle [degrees] }\end{array}$ & $\begin{array}{c}\text { Cohesion } \\
{[\mathrm{MPa}]}\end{array}$ \\
\hline $\begin{array}{l}\text { Medium-grained } \\
\text { sandstone }\end{array}$ & 63.7 & $29^{\circ} 33^{\prime}$ & 47.4 & 42.2 & $27^{\circ} 54^{\prime}$ & 46.6 \\
$\begin{array}{l}\text { Fine-grained } \\
\text { sandstone }\end{array}$ & 60.0 & $27^{\circ} 41^{\prime}$ & 44.5 & 45.3 & $25^{\circ} 55^{\prime}$ & 40.0 \\
\hline
\end{tabular}

Table 3 Internal friction angle $(\varphi)$ and cohesion (c) of sandstone in various states of water saturation for various values of normal stress.

\begin{tabular}{|c|c|c|c|c|c|c|c|}
\hline \multirow{3}{*}{\multicolumn{2}{|c|}{ Rock }} & \multicolumn{3}{|c|}{ Air-dry conditions } & \multicolumn{3}{|c|}{ Capillary saturation conditions } \\
\hline & & \multicolumn{3}{|c|}{ Normal stress } & \multicolumn{3}{|c|}{ Normal stress } \\
\hline & & $60 \mathrm{MPa}$ & $90 \mathrm{MPa}$ & $120 \mathrm{MPa}$ & $60 \mathrm{MPa}$ & $90 \mathrm{MPa}$ & $120 \mathrm{MPa}$ \\
\hline \multicolumn{2}{|c|}{$\mathrm{UCS}(\mathrm{p}=0 \mathrm{MPa})$} & \multicolumn{3}{|c|}{$63.7 \mathrm{MPa}$} & \multicolumn{3}{|c|}{$42.2 \mathrm{MPa}$} \\
\hline \multirow{2}{*}{ 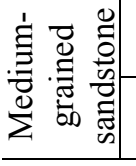 } & $\begin{array}{c}\varphi \\
\text { degrees }\end{array}$ & $31^{\circ} 59^{\prime}$ & $27^{\circ} 19^{\prime}$ & $24^{\circ} 14^{\prime}$ & $29^{\circ} 11^{\prime}$ & $24^{\circ} 57^{\prime}$ & $22^{\circ} 9^{\prime}$ \\
\hline & $\begin{array}{c}\mathrm{c} \\
\mathrm{MPa} \\
\end{array}$ & 43.6 & 51.5 & 58.4 & 42.3 & 49.2 & 55.2 \\
\hline \multicolumn{2}{|c|}{$\mathrm{UCS}(\mathrm{p}=0 \mathrm{MPa})$} & \multicolumn{3}{|c|}{$60.0 \mathrm{MPa}$} & \multicolumn{3}{|c|}{$45.3 \mathrm{MPa}$} \\
\hline \multirow{2}{*}{ 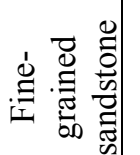 } & $\begin{array}{c}\varphi \\
\text { degrees }\end{array}$ & $31^{\circ} 12^{\prime}$ & $26^{\circ} 34^{\prime}$ & $23^{\circ} 31^{\prime}$ & $27^{\circ} 23^{\prime}$ & $23^{\circ} 17^{\prime}$ & $20^{\circ} 36^{\prime}$ \\
\hline & $\begin{array}{c}\mathrm{c} \\
\mathrm{MPa} \\
\end{array}$ & 41.3 & 49.1 & 55.8 & 37.9 & 44.4 & 50.0 \\
\hline
\end{tabular}

Cohesion and internal friction angle: we determined the cohesion and internal friction angle based on the results of the tests on sandstones in the conventional triaxial compression tests. The parameters were determined based on the equations of the parabolic envelope of Mohr's circles (Sanetra and Pacześniowski, 2006). It was assumed that the envelope of Mohr's circles is a parabola obtained with the least squares method. The internal friction angle and cohesion were calculated with an equation of the tangent line to the parabola in an assigned point for the medium-grained and fine-grained sandstone, both in the water capillary saturation state and in the so-called air-dry state. The equations of the parabolic envelope of Mohr's circles of the sandstone samples are presented in Table 1. The values of the internal friction angle and cohesion of the sandstone samples are presented in Table 2 .

The tests results show that the internal friction angle and cohesion decrease with the increase in water saturation level of the sandstone samples. In engineering geology this dependence has been determined for soils; here, we confirm a similar relationship for solid rocks of a productive Carboniferous series.

Based on the parabolic envelope determined during tests for a given rock (Table 1) it is possible to predict the behavior of the rock mass in any state of stress. Given the parameters of the equation of the parabola, the internal friction angle and the cohesion of sandstone for different values of normal stress were calculated. Table 3 shows the values of the internal 
friction angle and cohesion of the tested sandstones for normal stresses of 60, 90, and $120 \mathrm{MPa}$.

With the increase in normal stress, the internal friction angle decreases for the sandstones tested both in the air-dry state and the capillary saturation state, suggesting that the internal friction angle for rocks subjected to lower pressure, i.e. located in the shallower layers, is bigger than in the deeper rocks.

The cohesion of sandstones in the air-dry state ranged between 41.3 and $58.4 \mathrm{MPa}$, whereas for sandstones in the capillary saturation state the range was 37.9 to $55.2 \mathrm{MPa}$. Moreover, we observed that the fine-grained sandstone has lower values of internal friction angle and coherence than the medium-grained sandstone.

\section{SUMMARY}

Conventional triaxial compression tests with confining pressures of up to $40 \mathrm{MPa}$ allowed us to predict the behavior of the tested rock mass at a large depth. The tests also provide data on the behavior tendencies of deep rocks, which can lead to improved design of safe mining of various raw materials, including raw energy materials. The mining of resources is being extended deeper underground because of the gradual depletion of the shallower reserves and the restructuring of collieries in the biggest European coal basins.

We conducted tests that showed the tendencies of the changes in the stress and strain parameters resulting from confining pressure. Based on the results, we derived functional dependences and correlation coefficients for the tested rocks. The changes in the critical differential stress, differential residual stress, critical strain, and residual strain when the confining pressure was increased from 0 to $40 \mathrm{MPa}$ were described by linear functions with high correlation coefficients. The literature quoted in the paper shows that in most cases the confining pressure dependences are curvilinear. According to other researchers, the relationships for many sedimentary rocks may be described by a linear graph; our results agree with the latter studies.

Among the various geomechanical parameters, residual stress shows the highest dependency on the confining pressure. The residual stress shows the postpeak bearing capacity of the rock mass in areas of mining activity (e.g. load bearing zones of cracked pillars). The tests showed a 25 - to 78 -fold increase in the residual stress in confining pressures of 0 $40 \mathrm{MPa}$. We also confirmed that increases in some parameters resulting from an increase in the confining pressure were bigger for rocks of lower uniaxial compression strength.

The dependence of the post-peak failure modulus on the confining pressure within the range of 0 $40 \mathrm{MPa}$ for the tested sandstones in an air-dry state was described by a polynomial function. In the tests of sandstones in the capillary saturation state we did not obtain reliable results and further research is required in this area.
The tests showed that fine-grained sandstone has lower values of internal friction angle and cohesion compared with medium-grained sandstone. Through an analysis of the stress-strain curves we confirmed a general rule that the value of the internal friction angle of moistened rock is lower than that of finegrained sandstone.

It is worth noting that tests of USCB rocks in different states of humidity under conventional triaxial compression have not been conducted before. The results of the tests are important, from a practical point of view, for assessing the susceptibility of rock mass to rockbursts and water hazards in areas of the USCB that have a high water content, and operational collieries located in the vicinity of liquidated mines. Determining the cohesion and internal friction angle for the rocks is essential for solving many issues in the vast area of geoengineering. It concerns, among others, calculations of the stability of slopes and rock massifs. Moreover, the tests, along with fracturing measurements, provide important information for safe mining in opencast mines. They can be used to determine the bearing capacity of the rock or for construction purposes to evaluate the critical load of the subsoil, as well as for running safe mining activities in deep collieries to ensure the stability of underground operations in the presence of fracture zones in the rock mass around the operation zone.

\section{REFERENCES}

Ball, T. and Wysocka, M.: 2011, Radon in coalfields in the United Kingdom and Poland. Arch Min Sci, 56, 2, 249-264.

Bieniawski, Z.T.: 1971, Deformational behaviour of fractured rock under multiaxial compression. Proc Int Conf Structure Solid Mechanics and Engineering Design. John Wiley \& Sons London, 55, 1-10.

Bukowska, M. and Sanetra, U.: 2008, Conventional triaxial compression tests of granite and dolomite to determine their mechanical properties. Mineral Resources Management, 24, 2/3, 345-358.

Bukowski, P.: 2007, The method of investigations the gravity drainage capacity of solid and loose rocks). Patent application of Polish Patent Office, No PL 195518 B1. Patent application date - 28.09.2007, announced in WUP 09/07, 1-5, (in Polish).

Bukowski, P.: 2009, Determining water hazard zones for mining exploitation planned in the vicinity of reservoirs in abandoned mines. Mineral Resources Management, 25, 3, 203-215.

Bukowski, P.: 2010, Determining safety pillars in the vicinity of water reservoirs in mine workings within abandoned mines in the Upper Silesian Coal Basin (USCB). J Mining Science, 46, 3, 298-310.

Bukowski, P.: 2011, Water hazard assessment in active shafts in the Upper Silesian Coal Basin Mines. Mine Water and the Environmen,t 30, 4, 302-311.

Grmela, A. and Rapantova, N.: 2003, Protection of groundwater resources quality and quantity in mining areas. In Fabbri, A.G.; Gaal, G.; McCammon, RB (Eds.). Deposit and geoenvironmental models for resource exploitation and environmental security. 
Book series: NATO Science series. Partnership subseries 2. Environmental security, 80, 385-397.

Gustkiewicz, J. Ed.:1999, Physical properties of selected carboniferous rocks of Upper Silesian Coal Basin. Rocks of saddle beds. IGSMiE PAN, Kraków.

Kabiesz, J.: 2010, Prediction of mining-induced seismic activity with the use of neural networks on displacement field of rocks in its vicinity. Bondarenko V, Kovalevska I, Dychkovskyy R. (eds.) Conference of the School of Underground Mining, Ukraine, Sept 2010. New Techniques and Technologies in Mining, $175-187$.

Kovari, K, Tisa, A., Einstein, H.H. and Franklin, J.A.: 1983, Suggested methods for determining the strength of rock materials in triaxial compression. Revised version. Int J Rock Mech Min Sci \& Geomech, 20, 283-290.

Krause, E. and Smoliński, A.: 2013, Analysis and assessment of parameters shaping methane hazard in longwall areas. Journal of Sustainable Mining, 12(1), 13-19. DOI: 10.7424 /jsm130104

Kwaśniewski, M.: 2002, Behaviour of iso- and anisotropic rocks under triaxial compression conditions. Zeszyty Naukowe Politechniki Śląskiej Górnictwo 247, Gliwice, (in Polish).

Li, H.B., Zhao, J. and Li, T.J.: 1999, Triaxial compression tests on granite at different strain rates and confining pressures. Int J Rock Mech and Min Sci, 36 8, 10571063.

Łukaszewski, P.: 2007, Deformational properties of flysch sandstones under conventional triaxial compression conditions. Archives of Mining Sciences, 52(3), 371385.

Majcherczyk, T., Małkowski, P. and Niedbalski, Z.: 2005, Describing quality of rocks around underground headings: Endoscopic observations of fractures. Edited by: Konecny P, Conference: International Symposium of the International-Society-for-RockMechanics Location: Brno, CZECH REPUBLIC, EUROCK 2005: Impact of human activity on the geological environment, 355-360.

Majcherczyk, T., Małkowski, P. and Niedbalski, Z.: 2006, Speed of roof rock separation and a type of working's support. Edited by: Sobczyk EJ, Kicki J: Conference: International Mining Forum Location: Cracow, POLAND 2006; New Technological Solutions in Underground Mining: International Mining Forum 2006 Book Series: Proceedings and Monographs in Engineering, Water and Earth Sciences, 39-47.

Mogi, K.: 1964, Deformation and fracture of rocks under confining pressure. Bull Earthq Res Inst, Uni Tokyo, $42,491-514$.
Mogi, K.: 1971, Fracture and flow of rocks under high triaxial compression. J Geophys Res, 76, 1255-1269.

Paterson, M.S.: 1978, Experimental Rock Deformation: the Brittle Field. Springer-Verlag, Berlin, Heidelberg, New York.

Pinińska, J.: 2007, The need for high pressure rock tests for geological survey at great depths. Archives of Mining Sciences, 52 3, 281-296.

Rapantova, N. and Grmela, A.: 2003, Environmental impact of mine liquidation on groundwater and surface water. In Fabbri, A.G.; Gaal, G.; McCammon, RB (Eds.). Deposit and geoenvironmental models for resource exploitation and environmental security. Book series: NATO Science series. Partnership sub-series 2. Environmental security, 80, 365-384.

Sanetra, U. and Pacześniowski, K.: 2006, Calculation of internal friction angle and rock coherence by means of the method tangent to the envelope of Mohr's circles in the form of a parabola. Prace Naukowe GIG Górnictwo i Środowisko, 2, 23-34, (in Polish).

Stec, K.: 2009, Characteristics of the processes taking place at the sources of high energy tremors occurring in the Upper Silesian Coal Basin in Poland - regional character of the phenomenon. Tang C (ed.) 7th International Symposium on Rockburst and Seismicity in Mines. Dalian, China, Aug 2009. Controlling seismic hazard and sustainable development of deep mines. RASIM7, 1, 2, 415--426.

Stec, K.: 2012, Focal mechanisms of mine-induced seismic events, an explanation of geomechanical processes in the area of longwall 6, seam 510 in hard coal mine "Bobrek-Centrum". Archives of Mining Sciences, 57, 4, 871-886.

Ulusay, R. and Hudson, J.A. (eds.): 2007, The complete ISRM suggested methods for rock characterization, testing and monitoring: 1974-2006. Commission on testing methods ISRM.

Wysocka, M.: 2010, Investigations of outbursts and tremors in Polish collieries with application of radon measurements. Nukleonika, 55(4), 495-499. 